\title{
Effects of Cognitive-Behavioral Therapy on Empathy in Patients with Chronic Pain
}

\author{
Man-Kyu Song1, Soo-Hee Choi ${ }^{1,2}$, Do-Hyeong Lee', \\ Kyung-Jun Lee ${ }^{1}$, Won Joon Lee ${ }^{1}$, and Do-Hyung Kang ${ }^{1,2} \bowtie$ \\ ${ }^{1}$ Department of Neuropsychiatry, Seoul National University Hospital, Seoul, Republic of Korea \\ 2Department of Psychiatry, Seoul National University College of Medicine, Seoul, Republic of Korea
}

Objective Cognitive-behavioral therapy (CBT) is effective in patients with chronic pain. However, the efficacy of CBT for impaired empathy has not been studied in this population. We investigated the effect of CBT on empathy in patients with chronic pain.

Methods Patients with severe chronic pain were recruited. Empathy was assessed before and after CBT using the Interpersonal Reactivity Index (IRI). The patients underwent eight sessions over the course of 1 month conducted. Additional symptoms were assessed using the Short-Form McGill Pain Questionnaire (SF-MPQ), Beck Depression Inventory, Beck Anxiety Inventory, World Health Organization Quality of Life Scale Abbreviated Version, and the Scale for Suicide Ideation.

Results A total of 26 participants were included. Pre-CBT pain severity assessed using the SF-MPQ was significantly correlated with the IRI-empathic concern subscale score ( $\mathrm{p}=0.021)$, and the relationship remained significant after adjusting for sex, age, education level, and marital status. After CBT, the IRI-perspective-taking subscale scores $(\mathrm{p}=0.004)$ increased significantly and the IRI-personal distress subscale scores $(\mathrm{p}=0.013)$ decreased significantly in all participants. The SF-MPQ scores increased significantly $(\mathrm{p}=0.021)$.

Conclusion CBT improved empathy in patients with chronic pain independent of its effect on pain, suggesting that CBT is useful for improving interpersonal relationships in patients with chronic pain.

Psychiatry Investig 2018;15(3):285-291

Key Words Chronic pain, Cognitive-behavioral therapy, Empathy.

\section{INTRODUCTION}

Chronic pain is one of the most common health complaints and a significant risk to quality of life across age groups. In 2011, an estimated 100 million adults in the United States experienced chronic pain. ${ }^{1}$ Furthermore, a European study found that approximately 20 percent of the population complained of chronic pain in $2006 .^{2}$ A recent study conducted in South Korea found that $87.7 \%$ of females and $63.8 \%$ of males over the age of 60 years suffered from chronic pain. ${ }^{3}$ The direct and indirect costs of chronic pain are substantial. In Ireland in 2008, the total cost associated with pain was estimat-

Received: March 26, 2017 Revised: June 5, 2017

Accepted: July 3, 2017

$\triangle$ Correspondence: Do-Hyung Kang, MD, PhD

Department of Neuropsychiatry, Seoul National University Hospital, 101 Daehak-ro, Jongno-gu, Seoul 03080, Republic of Korea

Tel: +82-2-2072-0690, Fax: +82-2-744-9063, E-mail: basuare@daum.net

(c) This is an Open Access article distributed under the terms of the Creative Commons Attribution Non-Commercial License (http://creativecommons.org/licenses/bync/4.0) which permits unrestricted non-commercial use, distribution, and reproduction in any medium, provided the original work is properly cited. ed to be $€ 5 .{ }^{3}$ billion ( $3 \%$ of the GDP),${ }^{4}$ while in the United States the estimated annual national cost of chronic pain was \$560-635 billion in $2010 .{ }^{5}$ Collectively, pain places an enormous burden on the public health system and society; thus, active pain management strategies are of critical importance.

The International Association for the Study of Pain ${ }^{6}$ defines pain as an unpleasant sensory or emotional experience associated with actual or potential tissue damage or described in terms of such damage. Chronic pain is distinguished from acute pain by duration: pain lasting longer than 3 months is classified as chronic pain. ${ }^{7}$ Alternatively, chronic pain has been defined as lasting pain or pain that is inappropriately severe after recovery from tissue injury. ${ }^{8}$ Pain is a subjective experience that may be affected by emotion; thus, chronic pain may have an impact on a patient's mental health as well as his or her physical illness. Previous studies ${ }^{9-17}$ found that chronic pain could be caused by psychiatric conditions such as depression, anxiety disorder, and cognitive decline as well as sleep disorders, occupational difficulties, interpersonal distress, and a decrease in daily activity. Furthermore, chronic pain is asso- 
ciated with suicidal ideation and attempts, chronic fatigue, side effects caused by narcotic analgesics, opioid dependency, and economic difficulties. ${ }^{18-21}$ Recent studies showing that the emotional as well as the physical aspects of pain have an impact on aggravation and persistence ${ }^{22}$ have highlighted the need for health professionals such as psychologists, social workers, and physical therapists to participate in pain management. $^{23,24}$

Patients with chronic pain often reduce their daily activities and social interactions because of discomfort caused by pain, and they may become socially withdrawn. ${ }^{25,26}$ Recent studies have shown that chronic pain patients lack empathy, ${ }^{27}$ and that social emotion is impaired in patients with complex regional pain syndrome (CRPS) ${ }^{28}$ Empathy is the capacity to understand what another being is experiencing from within that being's frame of reference. Empathy has cognitive and affective components. The cognitive component involves understanding another person's perspective, and the affective component is an emotional response to another person's emotional state. ${ }^{29}$ Empathy is thought to play a central role in social interaction and interpersonal engagement as a fundamental component of social behavior. ${ }^{30}$ Because a lack of empathy is related to poor social functioning, ${ }^{31}$ increasing empathy in patients with chronic pain is central to improving their interpersonal relationships and quality of life. A previous study reported that improving emotional awareness in patients with chronic pain via cognitive-behavioral therapy (CBT) may in turn help improve their emotional empathic abilities, their regulation of the affective dimension of pain, and the overall quality of their social lives. Furthermore, effort-directed cognitive empathic abilities may help patients take greater control of their lives. ${ }^{27}$

CBT is a form of psychotherapy that has recently been used for patients with chronic pain. Several studies have reported that CBT improves pain and related problems, whether administered alone or in combination with medical treatment. Pain is affected by individual cognition as well as tissue injury, and the core premise of the therapy holds that maladaptive cognition contributes to the maintenance of emotional distress and behavioral problems. ${ }^{32}$ Previous studies have shown that CBT is effective for treating depression, anxiety, stress, and chronic pain. ${ }^{33-37}$ Additionally, CBT has been reported to improve quality of life and activities of daily living, chronic headache, facial pain, arthralgia, and fibromyalgia. ${ }^{38-42}$ CBT focuses on reducing pain and distress by modifying physical sensations, catastrophic thinking, and maladaptive behaviors. ${ }^{36}$

To our knowledge, no study has investigated the effectiveness of CBT in increasing empathy in chronic pain patients. Thus, we assessed the level of empathy and various psychiatric symptoms in patients with chronic pain before and after CBT.

\section{METHODS}

\section{Subjects}

We recruited 32 patients with severe chronic pain from the Seoul National University Hospital Psychiatric Pain Clinic: the majority were diagnosed with Complex Regional Pain Syndrome (CRPS, $\mathrm{n}=14$ ), and 8 with fibromyalgia, 6 with back pain, and 4 with headache. Severe pain was defined as a score greater than 7 on a 1-10 visual analogue scale (VAS). All participants were 19-65 years old and suffered from chronic pain lasting at least 3 months. None of the participants had an acute illness that may have affected their pain or psychiatric symptoms. Information concerning education level, occupation, and marital status were obtained. Of the 32 patients, 6 dropped out of CBT; thus, data from 26 patients (14 CRPS, 6 with fibromyalgia, 3 with back pain, and 3 with headache) who completed CBT and self-report questionnaires before and after CBT were included in the analysis. Twenty-three patients (88.5\%) had comorbid psychiatric disorders, including a depressive disorder $(n=20)$, or anxiety disorder $(n=3)$. The patients received routine care throughout the study. The study protocol was approved by the Seoul National University Hospital Institutional Review Board (Seoul, Korea, H-1707-023-867), and all participants provided informed consent before the study. All medical records were treated anonymously.

\section{CBT}

The patients received group CBT twice a week for a total of eight sessions during the 1-month study period. The details of the 8 sessions are given in Table 1. Groups were usually composed of 5 or 6 patients. Interventions were delivered by an experienced psychiatrist. We used mindfulness-based CBT, which has been found to reduce self-reported pain and painrelated behaviors in patients with chronic pain. ${ }^{43}$ The format of the sessions included a review of the previous session, introduction of new principles, review of the new content, and homework.

\section{Interpersonal Reactivity Index (IRI)}

The IRI was used to measure multiple dimensions of empathy. The IRI is a 28 -item self-report multidimensional scale that measures cognitive and emotional dimensions of empathy. The scale consists of four seven-item subscales, each tapping into an aspect of the global concept of empathy in which perspective taking (PT) and fantasy scale (FS) represent the cognitive dimension and empathic concern (EC) and personal distress (PD) represent the emotional dimension. The total scores for each subscale range from 0 to 28 . PT assesses the 
Table 1. Components of pain CBT program

\begin{tabular}{|c|c|}
\hline $\begin{array}{l}\text { Session } \\
\text { number }\end{array}$ & Session contents \\
\hline \multirow[t]{3}{*}{1} & Introduction to pain CBT \\
\hline & Abdominal breathing training \\
\hline & Learning to use the daily pain, mood, and activity charts \\
\hline \multirow[t]{2}{*}{2} & $\begin{array}{l}\text { Identifying automatic thoughts (reducing automatic } \\
\text { thoughts) }\end{array}$ \\
\hline & Progressive muscle relaxation (part I) \\
\hline \multirow[t]{3}{*}{3} & Evaluating automatic thoughts \\
\hline & Finding thinking errors \\
\hline & Progressive muscle relaxation (part II) \\
\hline \multirow[t]{2}{*}{4} & Correcting automatic thoughts \\
\hline & Progressive muscle relaxation (part III) \\
\hline \multirow[t]{2}{*}{5} & Understanding the core beliefs related to pain \\
\hline & Mindfulness meditation (part I) \\
\hline \multirow[t]{2}{*}{6} & Problem-solving strategies \\
\hline & Mindfulness meditation (part II) \\
\hline \multirow[t]{3}{*}{7} & Assertiveness skill training \\
\hline & Coping with stress-related pain \\
\hline & Mindfulness meditation (part III) \\
\hline \multirow[t]{2}{*}{8} & Final remarks \\
\hline & Strategies for preventing relapse \\
\hline
\end{tabular}

CBT: Cognitive-Behavioral Therapy

tendency to take the psychological point of view of others. The FS measures the tendency to get caught up in fictional stories and imagine the feelings and actions of fictitious characters in books, movies, and plays. EC assesses sympathy and concern for others. PD measures feelings of personal anxiety and unease intense interpersonal settings. ${ }^{31}$ The IRI is not intended to measure overall empathy, so each subscale should be used separately. It is instead intended to be used as a continuous measure of empathy-related dimensions, rather than to provide a categorical measure such as "high empathy" or "low empathy" ${ }^{44}$ The Korean version of the IRI has been validated. ${ }^{45}$

\section{Short-Form McGill Pain Questionnaire (SF-MPQ)}

Pain intensity was assessed using the SF-MPQ, a widely used short version of the MPQ. ${ }^{46}$ The main component of the SFMPQ consists of 15 descriptors (11 sensory and 4 affective), which are rated on an intensity scale from 0 (none) to 3 (severe). And the SF-MPQ includes a VAS and the Present Pain Intensity (PPI) index from the standard MPQ. ${ }^{47}$ The PPI is reported as a number ranging from 1 (mild) to 5 (excruciating). The Korean version of the SF-MPQ has been shown to be cross-culturally equivalent to the original questionnaire with demonstrated reliability and validity. ${ }^{48}$ In this study, the sum of the 15 descriptors was used to measure pain intensity.

\section{Other psychological tests}

Psychological symptoms before and after CBT were assessed using several scales. The Beck Depression and Anxiety Inventories (BDI and BAI, respectively) were used to evaluate depressive and anxiety symptoms, ${ }^{49,50}$ quality of life was assessed using the World Health Organization Quality of Life Scale Abbreviated Version (WHOQOL-BREF), ${ }^{51}$ and suicidal ideation was assessed using the Scale for Suicidal Ideation (SSI). ${ }^{52}$

\section{Statistical analysis}

The Statistical Package for the Social Sciences version 22.0 (IBM Corp., Armonk, NY, USA) was used to conduct the statistical tests. Demographic factors such as age, occupational status, marital status, and education level were compared according to sex using chi-square and independent t-tests. Pearson's correlation analysis was used to assess the pre-CBT associations among the SF-MPQ and IRI subscale scores. Furthermore, a partial correlation analysis was performed to assess the relationship between the SF-MPQ and IRI subscale scores, controlling for sex, age, educational level, occupation, and marital status. Pre- and post-CBT scores on the SF-MPQ, IRI, BDI, BAI, SSI, and WHOQOL were compared using paired t-tests; -values $<0.05$ were deemed to indicate statistical significance.

\section{RESULTS}

A total of 26 (12 male and 14 female) participants completed the study. The mean age was $45.12 \pm 6.50$ years (males, $42.50 \pm$ 3.40 years; females, $47.36 \pm 7.72$ years; $\mathrm{p}=0.055$ ). We found no significant differences between the sexes in age, education level, occupational status, or marital status. The subjects' demographic data, BDI, BAI, SSI, and WHOQOL-BREF scores are shown in Table 2.

The pre-CBT SF-MPQ pain severity score was significantly negatively correlated with the IRI-EC $(\mathrm{r}=-0.451, \mathrm{p}=0.021)$, but not the other subscales. IRI-PT showed a tendency to decrease as the SF-MPQ score increased, and IRI-PD tended to increase as the severity of pain increased (Figure 1). The partial correlation controlling for sex, age, education level, occupational status, and marital status revealed a significant negative correlation between SF-MPQ and IRI-EC $(r=-0.351, p=0.019)$.

The pre- and post-CBT scores for the IRI, SF-MPQ are shown in Figure 2. The pre- post-CBT comparison revealed that the IRI-PT score was significantly increased $(p=0.004)$ while the IRI-PD score was significantly decreased $(\mathrm{p}=0.013)$ after CBT. The SF-MPQ score was significantly higher $(\mathrm{p}=0.021)$ after $\mathrm{CBT}$, indicating that the therapy was associated with an increase in pain severity. The BDI, BAI, SSI, and WHOQOLBREF scores were $34.19 \pm 15.43,39.19 \pm 16.06,15.27 \pm 10.49$, 
and 53.38 \pm 12.30 , respectively, at pre-CBT. The BDI, BAI, SSI, and WHOQOL-BREF scores at post-CBT were $34.50 \pm 14.77$, $36.92 \pm 14.04,14.15 \pm 10.02$, and $58.27 \pm 9.58$, respectively. The
BDI $(\mathrm{t}=-0.192, \mathrm{p}=0.849)$, BAI $(\mathrm{t}=1.531, \mathrm{p}=0.138)$, SSI $(\mathrm{t}=1.657$, $\mathrm{p}=0.110)$ and WHOQOL-BREF scores $(\mathrm{t}=0.066, \mathrm{p}=0.948) \mathrm{did}$ not change significantly.

Table 2. Basic demographics and clinical characteristics

\begin{tabular}{|c|c|c|c|c|c|}
\hline & Male $(\mathrm{N}=12)$ & Female $(\mathrm{N}=14)$ & Total $(\mathrm{N}=26)$ & $\chi^{2}$ or $\mathrm{t}$ & $\mathrm{p}$-value \\
\hline Age (year $\pm S D)$ & $42.50 \pm 3.40$ & $47.36 \pm 13.21$ & $45.12 \pm 6.50$ & $\mathrm{t}=-2.014$ & 0.055 \\
\hline Education (year $\pm S D$ ) & $14.33 \pm 2.06$ & $13.21 \pm 2.30$ & $13.73 \pm 2.22$ & $\mathrm{t}=1.299$ & 0.206 \\
\hline Occupation (\%) & 83.3 & 71.4 & 76.9 & $\chi^{2}=0.516$ & 0.473 \\
\hline Living together (\%) & 66.7 & 85.7 & 76.9 & $\chi^{2}=1.321$ & 0.250 \\
\hline $\mathrm{BAI}($ mean $\pm \mathrm{SD})$ & $36.25 \pm 10.24$ & $41.71 \pm 19.81$ & $39.19 \pm 16.06$ & $\mathrm{t}=-0.861$ & 0.398 \\
\hline SSI (mean \pm SD) & $14.17 \pm 8.86$ & $16.21 \pm 11.96$ & $15.27 \pm 10.49$ & $\mathrm{t}=-0.489$ & 0.630 \\
\hline WHOQOL-BREF (mean \pm SD) & $56.33 \pm 8.65$ & $60.14 \pm 14.85$ & $53.38 \pm 12.30$ & $\mathrm{t}=-0.781$ & 0.442 \\
\hline
\end{tabular}

SD: standard deviation, BDI: Beck Depression Inventory, BAI: beck anxiety inventory, SSI: scale for suicidal ideation, WHOQOL-BREF: World Health Organization Quality of Life Scale Abbreviated Version
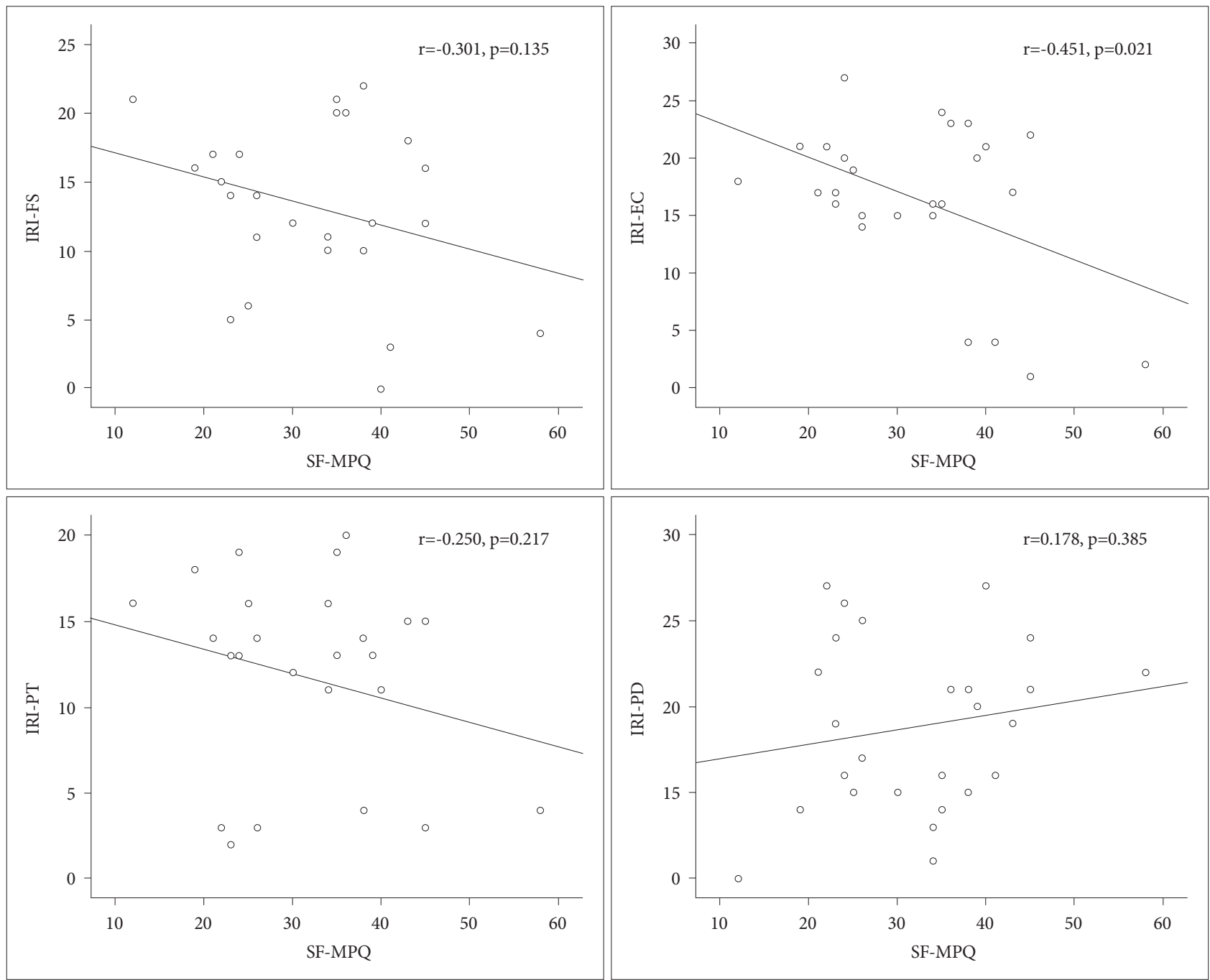

Figure 1. Correlation between SF-MPQ and IRI subscale scores at pre-treatment with cognitive behavioral therapy. SF-MPQ: Short FormMcGill Pain Questionnaire, IRI: Interpersonal Reactivity Index, FS: fantasy, EC: empathic concern, PT: perspective-taking, PD: personal distress. 


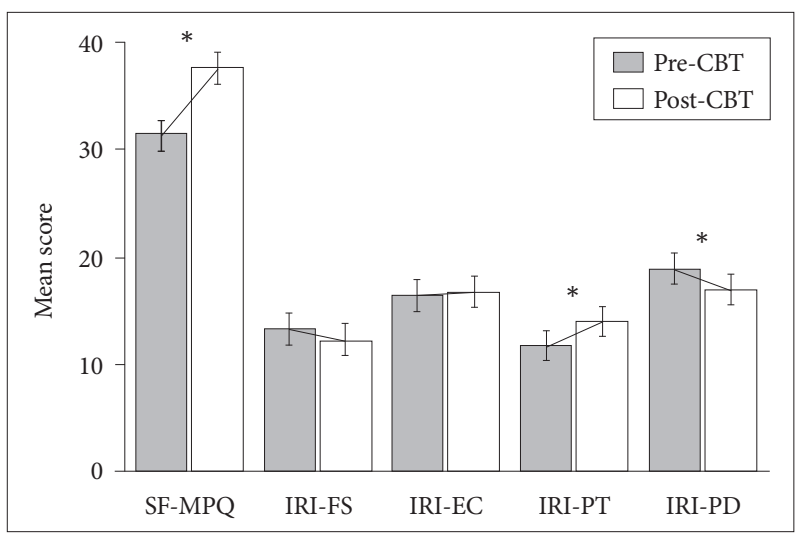

Figure 2. Interval changes in the SF-MPQ and IRI subscales at pre- and post-treatment with CBT. ${ }^{*} p<0.05$. CBT: cognitive-behavioral therapy, SF-MPQ: Short Form-McGill Pain Questionnaire, IRI: Interpersonal Reactivity Index, FS: fantasy, EC: empathic concern, PT: Perspective-Taking, PD: personal distress.

\section{DISCUSSION}

To our knowledge, our study is the first to investigate the effect of CBT on empathy in patients with chronic pain. We found that CBT increased empathy independent of its effect on pain. This finding is particularly significant in light of the fact that our patients experienced severe pain with scores greater than 7 on the VAS and indicates that CBT may be useful for improving interpersonal relationships and social interactions in chronic pain patients.

The IRI-PT score increased after CBT although the pain severity was not reduced. PT is the tendency to take the psychological point of view of others and is the core element of empathy. PT is related to concepts such as acceptance, nonstriving, and letting go, which are the attitudinal foundations of mindfulness practice. ${ }^{53}$ Kabat-Zinn said "We often waste energy denying. This actually prevents positive change from occurring, and it is important that we come around to a willingness to see things as they are. We are much more likely to know what to do and have the inner conviction to act when we have a clear picture of what is happening." ${ }^{34}$ Our findings suggest that CBT fostered the acceptance of pain and increased empathy in the patients. Individuals commonly try to fight pain; however, the struggle often aggravates the pain. Rather than denying pain or giving in to it, mindfulness focuses on the awareness and acceptance of pain. Patients are taught to be aware of pain and observe it calmly and closely. The acceptance of pain weakens its effect, and patients realize that they can control their pain themselves. Previous studies have found that the IRI-PT score was significantly associated with the length of ${ }^{55}$ and satisfaction ${ }^{56}$ with relationships among couples. Because PT involves understanding another's point of view, an increase in PT is associated with improvement in in- terpersonal interactions. Thus, we believe that by increasing the IRI-PT score, CBT will help improve the interpersonal relationships of patients with chronic pain.

The IRI-PD score decreased after CBT in our study. The IRI$\mathrm{PD}$ assesses self-oriented subjective anxiety when experiencing others in distress. Higher PD scores indicate greater individual distress, ${ }^{57}$ which may be caused by chronic pain. ${ }^{58}$ Thus, patients with chronic pain may not feel only individual distress but also others' negative experiences more negatively. ${ }^{27} \mathrm{Sev}-$ eral studies have shown that PD is related to negative emotionality and poorly regulated emotions ${ }^{59}$ which affect interpersonal relationships in chronic pain patients. In a functional magnetic resonance imaging study, Moriguchi et al. ${ }^{60}$ found a positive correlation between the IRI-PD score and blood oxygen level-dependent activity in the right temporal pole, which is associated with social behavior and function. ${ }^{61}$ Moreover, previous studies have shown a positive correlation between the severity of depression and IRI-PD scores, ${ }^{62}$ and that patients with CRPS had higher IRI-PD scores than healthy controls. ${ }^{27}$ $\mathrm{PD}$ and individual quality of life are inversely interrelated, ${ }^{27}$ which explains why higher PD scores are associated with poor interpersonal relationships. Thus, the fact that the IRI-PD score decreased after CBT suggests that the treatment had a positive effect on social function and individual quality of life in our patients.

Our finding that pain severity was increased after CBT is contrary to previous studies showing that CBT decreased pain severity in patients with chronic pain. ${ }^{38,40,42,63}$ The principles of mindfulness may account for this disparity. In mindfulnessbased CBT, the initial step in controlling pain is to focus on awareness of the pain and the emotions around it; thus, it may be that our finding reflects a temporary increase in pain severity. Nevertheless, we found that $\mathrm{CBT}$ increased empathy in patients with chronic pain. CBT has been used to treat pain, depression, and anxiety in patients with chronic pain; however, our findings suggest that the therapy may be useful for increasing empathy and improving social interactions in this population, particularly if offered early in the therapeutic course.

As mentioned previously, CBT is effective for treating depression and anxiety, and for improving quality of life. However, we found no significant change in the BDI, BAI, SSI, or WHOQOL-BREF scores. The reason for these results is because all participants had severe pain (a VAS score of over 7), and depression was more serious than in typical patients with chronic pain. The mean BDI score was 34.5 , which reflected a higher degree of depression in this study than in those reported previously (15-22) ${ }^{64,65} \mathrm{CBT}$ was conducted for patients with chronic pain over 4 weeks for a total of 8 hours, while the mean treatment duration was 6.74 weeks and the median number of hours of treatment was 16 in a review article..$^{33}$ The 
subjects in our study suffered from severe pain, so 1 month of CBT was insufficient to have an effect on depression, anxiety, or quality of life in these patients. To our knowledge, no study has investigated the relationship between CBT duration and psychological symptoms. Further investigations regarding this are needed in the future.

Our study, which shows for the first time that CBT increased empathy in patients with chronic pain, makes a significant contribution to the literature. Nevertheless, it has several limitations. First, our sample size was small, which may have resulted in selection bias. Second, we did not compare chronic pain patients with normal controls; thus, we were not able to determine whether the changes in empathy were quantitatively meaningful in relation to a healthy population. CBT promotes well-being and relieves perceived stress but, to date, no study has investigated the effect of empathy in a healthy group. Thus, it seems necessary to study the effect of CBT on empathy in patients with chronic pain and a healthy group. ${ }^{66}$ Third, the duration of our study, which included eight therapy sessions over the course of 1 month, was relatively short. Longitudinal investigations are necessary to evaluate the long-term effects of CBT on empathy in this population. Finally, we did not take into account the possible effects of medication. Future investigations in larger populations that include control subjects and consider several variables that may affect the results of CBT are warranted.

In conclusion, our investigation of the effect of CBT on empathy in patients with chronic pain showed that CBT increased IRI-PT scores and decreased IRI-PD scores independent of its effect on pain. These findings suggest that CBT is useful for improving interpersonal relationships and should be considered for patients with chronic pain. We recommend that clinicians consider the affective aspect of empathy in chronic pain patients, as it may be helpful in understanding the emotional distress and social difficulties that accompany chronic pain.

\section{Acknowledgements}

This research was supported by Basic Science Research Program through the National Research Foundation of Korea (NRF) funded by the Ministry of Science, ICT \& Future Planning (2014R1A1A1004553).

\section{REFERENCES}

1. Pizzo P, Clark N, Carter-Pokras O, Christopher M, Farrar JT, Follett KA, et al. Relieving Pain in America: A Blueprint for Transforming Prevention, Care. Washington D.C.: Education, and Research. OIM (Institute of Medicine); 2011.

2. Breivik H, Collett B, Ventafridda V, Cohen R, Gallacher D. Survey of chronic pain in Europe: prevalence, impact on daily life, and treatment. Eur J Pain 2006;10:287-333.

3. Jung CK, Park JY, Kim NS, Park HY. Status of chronic pain prevalence in the Korean adults. Public Health Weekly Report 2015;8:728-734.

4. Raftery MN, Ryan P, Normand C, Murphy AW, de la Harpe D, McGuire
BE. The economic cost of chronic noncancer pain in Ireland: results from the PRIME study, part 2. J Pain 2012;13:139-145.

5. Gaskin DJ, Richard P. The economic costs of pain in the United States. J Pain 2012;13:715-724.

6. Merskey H, Bogduk N. Classification of Chronic Pain, International Association for the Study of Pain Press. Seattle: International Association for Study of Pain Press (ISAP press); 1994.

7. Turk DC, Okifuji A. Psychological factors in chronic pain: evolution and revolution. J Consult Clin Psychol 2002;70:678-690.

8. Kang YK. Evaluation and management of chronic pain. J Korean Acad Fam Med 2003;24:103-111.

9. Campbell LC, Clauw DJ, Keefe FJ. Persistent pain and depression: a biopsychosocial perspective. Biol Psychiatry 2003;54:399-409.

10. Nicholson K, Martelli MF. The problem of pain. J Head Trauma Rehabil 2004;19:2-9.

11. Vogt BA. Pain and emotion interactions in subregions of the cingulate gyrus. Nat Rev Neurosci 2005;6:533-544.

12. Broggi G. Pain and Psycho-affective disorders. Neurosurgery 2008;62 (suppl 3):901-919; discussion 919-920.

13. Turk DC, Audette J, Levy RM, Mackey SC, Stanos S. Assessment and treatment of psychosocial comorbidities in patients with neuropathic pain. Mayo Clin Proc 2010;85(3 Suppl):S42-S50.

14. Maletic V, Raison CL. Neurobiology of depression, fibromyalgia and neuropathic pain. Front Biosci (Landmark Ed) 2009;14:291-5338.

15. Rainville J, Ahern DK, Phalen L, Childs LA, Sutherland R. The association of pain with physical activities in chronic low back pain. Spine (Phila Pa 1976) 1992;17:1060-1064.

16. Lee DH, Lee KJ, Cho KI, Noh EC, Jang JH, Kim YC, et al. Brain alterations and neurocognitive dysfunction in patients with complex regional pain syndrome. J Pain 2015;16:580-586.

17. Lee DH, Noh EC, Kim YC, Hwang JY, Kim SN, Jang JH, et al. Risk factors for suicidal ideation among patients with complex regional pain syndrome. Psychiatry Investig 2014;11:32-38.

18. Tang NK, Crane C. Suicidality in chronic pain: a review of the prevalence, risk factors and psychological links. Psychol Med 2006;36:575586.

19. Clauw DJ, Chrousos GP. Chronic pain and fatigue syndromes: overlapping clinical and neuroendocrine features and potential pathogenic mechanisms. Neuroimmunomodulation 1997;4:134-153.

20. Sehgal N, Manchikanti L, Smith HS. Prescription opioid abuse in chronic pain: a review of opioid abuse predictors and strategies to curb opioid abuse. Pain Physician 2012;15(3 Suppl):ES67-ES92.

21. Gaskin DJ, Richard P. The economic costs of pain in the United States. J Pain 2012;13:715-724.

22. Meagher MW, Arnau RC, Rhudy JL. Pain and emotion: effects of affective picture modulation. Psychosom Med 2001;63:79-90.

23. Gallagher RM. Treatment planning in pain medicine. Integrating medical, physical, and behavioral therapies. Med Clin North Am 1999;83: 823-849, viii.

24. Lande SD, Loeser JD. The future of pain management in managed care. Manag Care Interface 2001;14:69-75.

25. Cano A, Williams AC. Social interaction in pain: reinforcing pain behaviors or building intimacy? Pain 2010;149:9-11.

26. May A. Chronic pain may change the structure of the brain. Pain 2008; 137:7-15.

27. Sohn HS, Lee DH, Lee KJ, Noh EC, Choi SH, Jang JH, et al. Impaired empathic abilities among patients with complex regional pain syndrome (Type I). Psychiatry Investig 2016;13:34-42.

28. Shin NY, Kang D-H, Jang JH, Park SY, Hwang JY, Kim SN, et al. Impaired recognition of social emotion in patients with complex regional pain syndrome. J Pain 2013;14:1304-1309.

29. Preston SD, de Waal FB. Empathy: its ultimate and proximate bases. Behav Brain Sci 2002;25:1-20.

30. Derntl B, Finkelmeyer A, Eickhoff S, Kellermann T, Falkenberg DI, Schneider F, et al. Multidimensional assessment of empathic abilities: 
neural correlates and gender differences. Psychoneuroendocrinology 2010;35:67-82.

31. Davis MH. Measuring individual differences in empathy: evidence for a multidimensional approach. J Pers Soc Psychol 1983;44:113-126.

32. Hofmann SG, Asnaani A, Vonk IJ, Sawyer AT, Fang A. The efficacy of cognitive behavioral therapy: a review of meta-analyses. Cognit Ther Res 2012;36:427-440.

33. Morley S, Eccleston C, Williams A. Systematic review and meta-analysis of randomized controlled trials of cognitive behaviour therapy and behaviour therapy for chronic pain in adults, excluding headache. Pain 1999;80:1-13.

34. Butler AC, Chapman JE, Forman EM, Beck AT. The empirical status of cognitive-behavioral therapy: a review of meta-analyses. Clin Psychol Rev 2006;26:17-31.

35. Wetherell JL, Afari N, Rutledge T, Sorrell JT, Stoddard JA, Petkus AJ, et al. A randomized, controlled trial of acceptance and commitment therapy and cognitive-behavioral therapy for chronic pain. Pain 2011;152: 2098-2107.

36. Hofmann SG, Asnaani A, Vonk IJ, Sawyer AT, Fang A. The Efficacy of Cognitive Behavioral Therapy: a review of meta-analyses. Cognit Ther Res 2012;36:427-440.

37. Lee DH, Park HY, Lee US, Lee KJ, Noh EC, Jang JH, et al. The effects of brain wave vibration on oxidative stress response and psychological symptoms. Compr Psychiatry 2015;60:99-104.

38. Hoffman BM, Papas RK, Chatkoff DK, Kerns RD. Meta-analysis of psychological interventions for chronic low back pain. Health Psychol 2007;26:1-9.

39. Andrasik F, Grazzi L, Usai S, Bussone G. Pharmacological treatment compared to behavioural treatment for juvenile tension-type headache: results at two-year follow-up. Neurol Sci 2007;28(Suppl 2):S235-S238.

40. Aggarwal VR, Lovell K, Peters S, Javidi H, Joughin A, Goldthorpe J. Psychosocial interventions for the management of chronic orofacial pain. Cochrane Database Syst Rev 2011;(11):CD008456.

41. Astin JA, Beckner W, Soeken K, Hochberg MC, Berman B. Psychological interventions for rheumatoid arthritis: a meta-analysis of randomized controlled trials. Arthritis Rheum 2002;47:291-302.

42. Glombiewski JA, Sawyer AT, Gutermann J, Koenig K, Rief W, Hofmann SG. Psychological treatments for fibromyalgia: a meta-analysis. Pain 2010;151:280-295.

43. Kabat-Zinn J, Lipworth L, Burney R. The clinical use of mindfulness meditation for the self-regulation of chronic pain. J Behav Med 1985;8: 163-190.

44. Konrath S. A critical analysis of the Interpersonal Reactivity Index. MedEdPORTAL Directory and Repository of Educational Assessment Measures (DREAM); 2013.

45. Kang I, Kee S, Kim SE, Jeong B, Hwang JH, Song JE, et al. Reliability and validity of the Korean-version of Interpersonal Reactivity Index. J Korean Neuropsychiatr Assoc 2009;48:352-358.

46. Dworkin RH, Turk DC, Revicki DA, Harding G, Coyne KS, PeirceSandner S, et al. Development and initial validation of an expanded and revised version of the Short-form McGill Pain Questionnaire (SFMPQ-2). Pain 2009;144:35-42.

47. Melzack R. The short-form McGill pain questionnaire. Pain 1987;30:
191-197.

48. Choi SA, Son C, Lee JH, Cho S. Confirmatory factor analysis of the Korean version of the short-form McGill pain questionnaire with chronic pain patients: a comparison of alternative models. Health Qual Life Outcomes 2015;13:15

49. Beck AT, Steer RA, Carbin MG. Psychometric properties of the Beck Depression Inventory: twenty-five years of evaluation. Clin Psychol Rev 1988;8:77-100.

50. Beck AT, Epstein N, Brown G, Steer RA. An inventory for measuring clinical anxiety: psychometric properties. J Consult Clin Psychol 1988; 56:893-897.

51. Harper A. Development of the World Health Organisation WHOQOL-BREF quality of life assessment. Psychol Med 1998;28:551-558.

52. Beck AT, Kovacs M, Weissman A. Assessment of suicidal intention: the Scale for Suicide Ideation. J Consult Clin Psychol 1979;47:343-352.

53. Kabat-Zinn J. Wherever You Go, There You Are: Mindfulness Meditation in Everyday Life. New York: Hyperion; 1994.

54. Kabat-Zinn J, Hanh TN. Full Catastrophe Living: Using the Wisdom of Your Body and Mind to Face Stress, Pain, and Illness. New York: Delta; 2009.

55. Davis MH, Oathout HA. Maintenance of satisfaction in romantic relationships: empathy and relational competence. J Pers Soc Psychol 1987; 53:397-410.

56. Franzoi SL, Davis MH, Young RD. The effects of private self-consciousness and perspective taking on satisfaction in close relationships. J Pers Soc Psychol 1985;48:1584-1594.

57. Davis MH, Association AP. A Multidimensional Approach to Individual Differences in Empathy. Washington D.C.: American Psychological Association; 1980 .

58. Keefe FJ, Lumley M, Anderson T, Lynch T, Carson KL. Pain and emotion: new research directions. J Clin Psychol 2001;57:587-607.

59. Mooradian TA, Davis M, Matzler K. Dispositional empathy and the hierarchical structure of personality. Am J Psychol 2011;124:99-109.

60. Moriguchi Y, Ohnishi T, Lane RD, Maeda M, Mori T, Nemoto K, et al. Impaired self-awareness and theory of mind: an fMRI study of mentalizing in alexithymia. Neuroimage 2006;32:1472-1482.

61. Bachevalier J. Medial temporal lobe structures and autism: a review of clinical and experimental findings. Neuropsychologia 1994;32:627-648.

62. Berthoz S, Wessa M, Kedia G, Wicker B, Grèzes J. Cross-cultural validation of the empathy quotient in a French-speaking sample. Can J Psychiatry 2008;53:469-477.

63. Andrasik F. What does the evidence show? Efficacy of behavioural treatments for recurrent headaches in adults. Neurol Sci 2007;28(Suppl 2): S70-S77.

64. Glombiewski JA, Hartwich-Tersek J, Rief W. Depression in chronic back pain patients: prediction of pain intensity and pain disability in cognitive-behavioral treatment. Psychosomatics 2010;51:130-136.

65. Mangels M, Schwarz S, Worringen U, Holme M, Rief W. Evaluation of a behavioral-medical inpatient rehabilitation treatment including booster sessions: a randomized controlled study. Clin J Pain 2009;25:356-364.

66. Smith BW, Shelley BM, Dalen J, Wiggins K, Tooley E, Bernard J. A pilot study comparing the effects of mindfulness-based and cognitive-behavioral stress reduction. J Altern Complement Med 2008;14:251-258. 